\title{
Modelling of the Ebro River plume. Validation with field observations*
}

\author{
MARC MESTRES ${ }^{1}$, JOAN PAU SIERRA ${ }^{1}$, AGUSTÍN SÁNCHEZ-ARCILLA ${ }^{1}$, \\ JULIO GONZÁLEZ DEL RÍO², THOMAS WOLF³, ANDRÉS RODRÍGUEZ ${ }^{4}$ \\ and SYLVAIN OUILLON ${ }^{5}$
}

\author{
${ }^{1}$ Laboratori d'Enginyeria Marítima, Universitat Politècnica de Catalunya, C/ Jordi Girona 1-3, Campus Nord Mòdul D-1, \\ 08034 Barcelona, Spain. E-mail: marc.mestres@upc.es \\ ${ }_{2}^{2}$ Laboratorio de Tecnologías del Medio Ambiente, Universidad Politécnica de Valencia, Camino de Vera s/n, \\ 46020 Valencia, Spain. \\ ${ }^{3}$ Institute for Lake Research. Dept. Hydrology \& Lake Physics, Argenweg 50/1, D-88085 Langenargen, Germany. \\ ${ }^{4}$ Laboratorio de Hidráulica, FCEFyN, Universidad Nacional de Córdoba, Ciudad Universitaria, Av. Vélez Sarsfield 1600, \\ 5000 Córdoba, Argentina. \\ ${ }^{5}$ Centre IRD Nouméa, BP A5, 98848 Nouméa, New Caledonia
}

\begin{abstract}
SUMMARY: The spreading of the plume induced by the freshwater discharge from the Ebro River into northwestern Mediterranean coastal waters was modelled using two numerical codes. The coastal current field was obtained with a finite difference hydrodynamic model based on a steady-state version of the shallow-water equations, whereas the freshwater dispersion was calculated with a Lagrangian code that solves the 3D convection-diffusion equation and reproduces turbulent diffusion using a "random-walk" algorithm. The agreement obtained between numerical results, satellite observations and field measurements allows an analysis of the more relevant physical mechanisms and the corresponding "tuning" of the two models. The results show that local hydrodynamics near the river mouth, and consequently the spreading of the river plume, are highly dependent on the driving river discharge and wind field characteristics.
\end{abstract}

Key words: Ebro River, river plume, numerical modelling, hydrodynamics, dispersion.

RESUMEN: Modelado del PenaCho del Río EbRo. VAlidación CON MEDidas de CAMPO. - Se presenta la simulación del penacho de agua dulce resultante de la descarga del río Ebro en el Mediterráneo mediante el uso secuencial de dos modelos numéricos. La hidrodinámica costera ha sido obtenida con un modelo en diferencias finitas, basado en una versión estacionaria de las ecuaciones para aguas someras, mientras que la dispersión del agua aportada por el Ebro se ha calculado con un modelo lagrangiano de partículas que resuelve la ecuación de transporte 3D. El ajuste obtenido entre los resultados numéricos, medidas de campo y observaciones desde satélite permiten analizar los mecanismos físicos más relevantes, así como realizar el correspondiente calibrado de ambos modelos. Los resultados muestran que la hidrodinámica local cerca de la desembocadura del río y, por consiguiente, la dispersión del penacho del río, dependen principalmente del volumen de descarga del río y de la características del viento dominante.

Palabras clave: río Ebro, penacho de agua dulce, modelado numérico, hidrodinámica, dispersión.

\section{INTRODUCTION}

One of the most common mesoscale features of continental and shelf seas are the estuary plumes

*Received January 23, 2003. Accepted July 8, 2003. produced by the continuous discharge of brackish or freshwater from a coastal buoyancy source, such as a river or estuary. Just like estuaries, these structures are highly dynamic regions with significant salinity gradients, in which a number of important processes such as biological production and mixing can take 
place (Morris et al., 1995). Their effects on coastal waters range from reducing salinity to changing the distribution of parameters such as particulate and dissolved matter, pollutants, nutrients, phytoplankton, zooplankton and larvae (Jouanneau and Latouche, 1982; Fichez et al., 1992; Grimes and Kingsford, 1996; Durand et al., 2002; Froidefond et al., 1998; Broche et al., 1998).

The general spreading of freshwater plumes depends on a large number of factors. Garvine (1995) proposed a classification scheme for unforced plumes based on five independent bulk parameters defined by the inlet breadth, depth and velocity, the Coriolis parameter, the salinity difference, the bottom slope and the tidal amplitude. In the absence of wind and currents, he found that the most important parameter was the Kelvin number $K$, defined as the ratio of a primary physical lengthscale to the baroclinic Rossby radius. Discharges with $K$ $<<1$ are characterised by strongly non-linear flow dynamics and sharp frontal boundaries and internal hydraulic jumps, whereas those with $K \gg 1$ have linear dynamics and across-shore geostrophic balance. A different classification scheme was suggested by Yankovsky and Chapman (1997), using the plume's vertical structure and discriminating between bottom- and surface-advected plumes. Chao (1988) classified plumes as supercritical or subcritical, depending on the value of an internal Froude number; he also analysed the effects of the wind and the bottom slope on the plume. Wind forcing was also included in the work of Fennel and Mutzke (1997) and Kourafalou et al. (1996a), the former also taking into account the waterbody stratification. Garcia Berdeal et al. (2002) considered both the wind forcing and the effects of ambient flow in their analysis of high discharge river plumes. River plumes in alongshore currents were studied by Garvine (1987), and Kourafalou et al. (1996b) and Lentz and Limeburner (1995) both studied the effects on freshwater discharges of tide- and winddriven circulation. Other authors (e.g. Marsaleix et $a l ., 1998)$ have attempted to clarify the role played by the continental shelf topography in plume shape.

Most of the referenced plume studies have used approaches based on numerical modelling, although others have relied on the analysis of satellite imagery, or a combination of both (Chao and Boicourt, 1986; O'Donnell, 1990; Stumpf et al., 1993; Kourafalou et al., 1996a,b; Estournel et al., 1997; Lazure and Jegou, 1998; Marsaleix et al., 1998; Froidefond et al., 1998; Siegel et al., 1999).

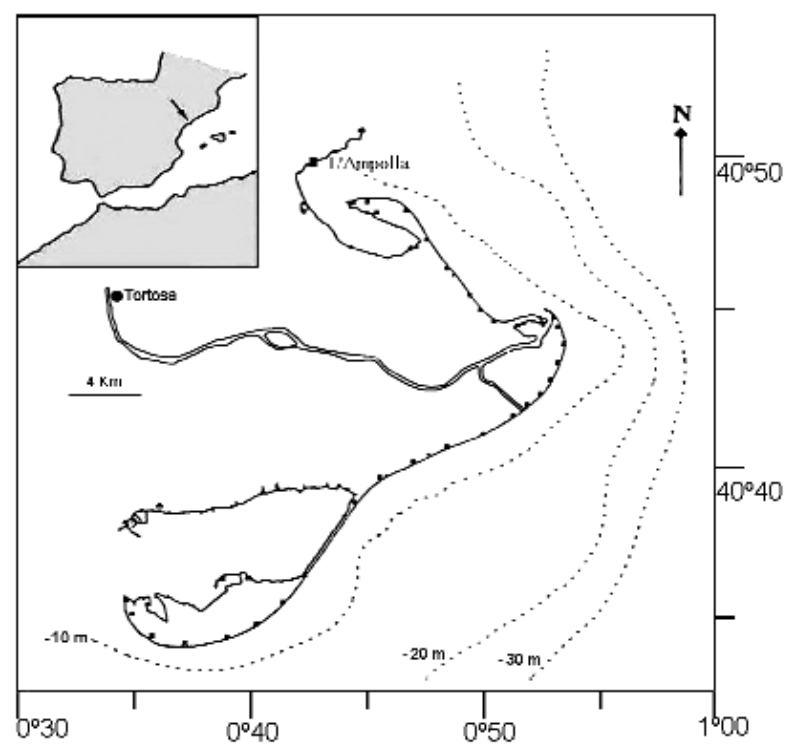

FIG. 1. - Delta of the Ebro River, on the northeastern Spanish Mediterranean coast.

In this context, various model types have been used to study river-generated plumes. Several authors (Chao and Boicourt, 1986; Chao, 1987, 1988; Weaver and Hsieh; 1987, Johns et al., 1992; Pinazo et al., 1996) have focused on three-dimensional primitive-equation models, taking into account the nonlinear dynamics of the flow. The associated turbulent mixing is usually included through refined turbulence closure schemes (Oey and Mellor, 1993; Baumert et al., 1997; Burchard and Bolding, 2001; Umlauf et al., 2003; Luyten et al., 1996). The weakness of these models lies in the use of fixed horizontal grids to solve the equations, which does not enable an accurate representation of the frontal discontinuity bounding the plume (Estournel et al., 1997).

An alternative type of model focuses on the computation of the plume frontal propagation, solving a system of hyperbolic equations by the method of characteristics (Garvine, 1987; O’Donnell, 1990). These models consider the plume as a body of constant density, thin with respect to the water column depth and bounded by a frontal discontinuity. They are particularly useful for the calculation of this frontal propagation but appear to be weaker than primitive-equation models with respect to the treatment of atmospheric forcing, turbulence, density gradients and coastal circulation surrounding the plume (Estournel et al., 1997).

In this paper, the spreading of the Ebro River plume in the northwestern Mediterranean Sea (Fig. 1) will be analysed through numerical modelling although, as will be seen, following a different 
approach from the aforementioned models. A 3D hydrodynamic model and a Lagrangian particle transport model, which are briefly described below, were coupled and used to simulate the evolution of the freshwater discharged by the river into coastal waters. The separate use of relatively simple numerical models is computationally less complex and expensive than attempting to solve simultaneously all the relevant equations (salinity transport, momentum and continuity) and, as will be shown below, yields reasonable results which are comparable to field measurements.

Although previous studies on the spreading of the Ebro River plume have been made (e.g. Xing and Davies, 2002; Durand et al., 2002), they were either based on an idealised representation of the bottom topography or focused on suspended matter transport. To the authors' knowledge, this is the first study in which the actual bathymetry of the Ebro delta is used to simulate the freshwater dispersion, and the obtained numerical results compared to field measurements of salinity.

\section{Numerical models}

\section{Hydrodynamic model}

The hydrodynamic model (TRIM3D) is based on a semi-implicit finite difference scheme for the governing primitive variable equations. These equations describe constant-density free surface flows and are derived from the Navier-Stokes equations after turbulent averaging,

$$
\begin{gathered}
\frac{\partial u}{\partial t}+u \frac{\partial u}{\partial x}+v \frac{\partial u}{\partial y}+w \frac{\partial u}{\partial z}= \\
=-\frac{\partial p}{\partial x}+v_{H}\left(\frac{\partial^{2} u}{\partial x^{2}}+\frac{\partial^{2} u}{\partial y^{2}}\right)+\frac{\partial}{\partial z}\left(v_{V} \frac{\partial u}{\partial z}\right)+f v \\
\frac{\partial v}{\partial t}+u \frac{\partial v}{\partial x}+v \frac{\partial v}{\partial y}+w \frac{\partial v}{\partial z}= \\
=-\frac{\partial p}{\partial y}+v_{H}\left(\frac{\partial^{2} v}{\partial x^{2}}+\frac{\partial^{2} v}{\partial y^{2}}\right)+\frac{\partial}{\partial z}\left(v_{V} \frac{\partial v}{\partial z}\right)-f u \\
\frac{\partial w}{\partial t}+u \frac{\partial w}{\partial x}+v \frac{\partial w}{\partial y}+w \frac{\partial w}{\partial z}= \\
=-\frac{\partial p}{\partial z}+v_{H}\left(\frac{\partial^{2} w}{\partial x^{2}}+\frac{\partial^{2} w}{\partial y^{2}}\right)+\frac{\partial}{\partial z}\left(v_{V} \frac{\partial w}{\partial z}\right)
\end{gathered}
$$

$$
\frac{\partial u}{\partial x}+\frac{\partial v}{\partial y}+\frac{\partial w}{\partial z}=0
$$

where $u, v, w$ are the components of the velocity vector, $v_{H}$ and $v_{V}$ are the horizontal and vertical turbulent viscosities, and $f$ is the Coriolis parameter.

The model formulation also includes the following free-surface equation:

$$
\frac{\partial \eta}{\partial t}+\frac{\partial}{\partial x}\left(\int_{-h}^{\eta} u d z\right)+\frac{\partial}{\partial y}\left(\int_{-h}^{\eta} v d z\right)=0
$$

where $\eta$ is the free surface level and $h$ is the depth, and boundary conditions at the free surface and at the sea bed are specified by the prescribed wind and bottom (friction) stresses respectively.

After assuming that the pressure $p(x, y, z)$ can be expressed as the sum of a hydrostatic component $g[\eta(x, y, t)-z)]$ and a hydrodynamic component $q(x$, $y, z)$, the set of equations is solved using a fractional step scheme. In the first step, the hydrodynamic component of the pressure is neglected, whereas the gradient of surface elevation (in the horizontal momentum equations) and the velocity (in the free surface equation) are discretised implicitly for the sake of stability. In the second step, the provisional computed velocity is corrected by adding the hydrodynamic pressure gradient, calculated after imposing that the resulting velocity field is divergence-free throughout the computational domain, which leads to a finite difference Poisson equation that is solved iteratively using the preconditioned conjugate gradient method. The detailed numerical solution procedure can be found in Casulli and Stelling (1996).

\section{Transport model}

The dispersion of the river plume is simulated using a transport model based on a Lagrangian approach to the convection-diffusion equation:

$$
\frac{\partial C}{\partial t}+u_{i} \frac{\partial C}{\partial x_{i}}=\frac{\partial^{2}}{\partial x_{i} x_{j}}\left(K_{i j} C\right)+D S
$$

where $C$ is the concentration, $u_{i}$ are the components of the velocity, $K_{i j}$ are the components of the turbulent diffusivity tensor, and $D S$ is a source term which accounts for processes such as sediment settling. Since in this paper only salinity transport is studied, this last term will not be employed here.

A Lagrangian formulation is suitable in this case because the freshwater plume will only occupy part 
of the computational domain and because mass conservation is implicit within the computational scheme. The numerical code solves a discretisation of the 3D Fokker-Planck equation (Tompson and Gelhar, 1990)

$$
\boldsymbol{r}_{n}=\boldsymbol{r}_{n-1}+\boldsymbol{A}\left(\boldsymbol{r}_{n-1}, t_{n-1}\right) \Delta t+\boldsymbol{B}\left(\boldsymbol{r}_{n-1}, t_{n-1}\right) \sqrt{\Delta t} \boldsymbol{Z}_{n}
$$

in which $\boldsymbol{r}_{\boldsymbol{n}}$ is the position of each Lagrangian element at time $t_{n}, \boldsymbol{A}$ is a deterministic forcing vector acting on each individual particle, $\boldsymbol{B}$ is a deterministic scaling matrix and $\boldsymbol{Z}$ is a vector of independent random numbers. The continuous form of (7) is equivalent to (6) when

$$
A_{i}=u_{i}+\frac{\partial K_{i j}}{\partial x_{j}} ; \quad B_{i k} B_{j k}=2 K_{i j}
$$

Equation (7) can formally be written as

$$
x_{n}^{i}=x_{n-1}^{i}+u_{n-1}^{i} \Delta t
$$

where now $u_{n-l}^{j}(\mathrm{j}=1,2)$ are horizontal "velocities", and $u_{n-1}^{3}$ is the vertical "velocity". The turbulent velocities are computed using a random-walk algorithm, such as

$$
u_{t}^{i}=2\left(R_{01}-1\right) \sqrt{\frac{6 K_{i}}{\Delta t}}
$$

where $R_{01}\left(0 \leq R_{01} \leq 1\right)$ is a random number, given by a random number generator, and the diffusion coefficient is given as (Holly, 1985):

$$
\begin{array}{lc}
K_{L}=c_{L} u_{*} d \quad & \text { (longitudinal) } \\
K_{T}=c_{T} u_{*} d \quad(\text { transverse) } \\
K_{V}=c_{V} u_{*} d \quad \text { (vertical) }
\end{array}
$$

where $c_{L}, c_{T}$, and $c_{V}$ are experimental coefficients, $u_{*}$ is the friction velocity and $d$ is a typical length scale (usually the local depth). A large range of empirical values can be found in the literature for these coefficients $c_{L}, c_{T}$ and $c_{V}$ (e.g. Holly, 1985).

The concentration value at a given location is obtained from the cloud of discrete Lagrangian elements using two different mapping functions included in the model. Both algorithms-the Box-Counting (BC) method and Smoothed-Particle Hydrodynamics (SPH, Gingold and Monaghan, 1982)—consider only the mass contribution of those particles found within a certain region centred at the evaluation point. In the $\mathrm{BC}$ method, this integration region is defined by specifying a complete volume; in the
SPH method, an integration length must be specified. A detailed description of the model and methods can be found in Mestres (2002).

\section{Physical features of the Ebro Delta area}

The Ebro River crosses the northeastern quarter of the Spanish peninsula, collecting the surface waters of over 350 minor rivers and draining a basin of approximately $85,362 \mathrm{~km}^{2}$. It discharges into the Spanish Mediterranean coastal waters at a rate which varies largely with seasons (Sierra et al., 2003). The lower course discharge, however, has been reduced in the last decades due to the construction of several dams and the corresponding increase of water demand and river regulation. It has been estimated that the mean annual flow in the lower Ebro River has been reduced by $29 \%$ during the $20^{\text {th }}$ century due to increased water use and evaporation from reservoirs (Ibáñez et al., 1996).

According to the Ebro River authority, during the $1960-90$ period the yearly mean discharge rate was $424 \mathrm{~m}^{3} / \mathrm{s}$, showing a monthly average maximum in February $\left(662 \mathrm{~m}^{3} / \mathrm{s}\right)$ and a minimum in August (135 $\mathrm{m}^{3} / \mathrm{s}$ ). All these flows were measured at Tortosa, 42 $\mathrm{km}$ upstream from the river mouth. When only the period 1980-90 is taken into account, these discharges are reduced to $300 \mathrm{~m}^{3} / \mathrm{s}$ (annual average), $461 \mathrm{~m}^{3} / \mathrm{s}$ (monthly average maximum) and $119 \mathrm{~m}^{3} / \mathrm{s}$ (monthly average minimum). It should be stressed that during the last few years daily mean discharge rates larger than $2,000 \mathrm{~m}^{3} / \mathrm{s}$ have seldom been observed during floods.

The Ebro Delta is located on a transition area between a narrow stretch of continental shelf (approximately $10 \mathrm{~km}$ wide) in the north, and a broader region (about $50 \mathrm{~km}$ wide) in the south. The mean circulation over the shelf is characterised by a quasi-permanent southwestwards slope current in geostrophic equilibrium (Font et al., 1990; Salat et $a l ., 2002)$, plus an additional non-geostrophic component due to non-linear interactions, such as friction with boundaries.

Wind conditions are a major forcing agent for the local circulation in this area (Garcia and Ballester, 1984). Nevertheless, wind effects in shallow waters are affected by ambient stratification, and measurements at larger depths suggest (Font, 1990; Font et $a l .$, 1995) that wind influence is almost negligible for frequencies lower than inertial, and that flow variability at deep levels is largely driven by the density field. 
Predominant wind stress fields in the Ebro Delta area are generated by south and southwest winds in the summer, whereas during the winter season the most frequent winds blow from the northwest (although the strongest winds blow from the east). Correspondingly, the wave climate in this area also shows a very defined seasonal structure, with three main directions (E-NE, S, and NW) for the incident wave field (García et al., 1993). The yearly averaged significant wave height and mean period are $0.75 \mathrm{~m}$ and $3.9 \mathrm{~s}$ respectively. Nearly all mean periods have values between 2 and $8 \mathrm{~s}$, although maximum peak periods of about $11 \mathrm{~s}$ have been observed during storms (Jiménez, 1996).

The maximum astronomical tide range in the area is about $0.25 \mathrm{~m}$, with an average value of 0.16 $\mathrm{m}$, allowing the Ebro Delta region to be classified as a micro-tidal environment.

\section{Field campaigns in the Ebro River plume}

During 1999-2000, several field campaigns took place in the coastal area of the Ebro Delta, including the river, within the framework of a European Union research project. These campaigns were aimed at studying the hydrodynamics of the estuary and the coastal region, focusing on the spreading of the river plume under different (seasonal) wind, sea and river discharge conditions.

The two campaigns that are of concern here are those undertaken in July 1999 and February 2000 (i.e. summer and winter campaigns). A complete description of these field campaigns can be found in Martínez et al. (1999, 2000), and only a brief glimpse of their particular characteristics will be given here.

The first campaign took place in July 1999. It included hydrodynamic and water quality measurements under summer conditions, both in the river plume and in the estuary (to approximately $19 \mathrm{~km}$ upstream from the river mouth). The second campaign was undertaken during the first week in February 2000, and included similar measurements under winter conditions.

The hydrodynamic measurements consisted of detailed 3D current velocity data in the estuary. CTD profiles were taken within the river domain (to describe the salt wedge behaviour) and inside the river plume region. Salinity, $\mathrm{pH}$ and temperature profiles were also obtained using a multiparametric probe. Water sampling at various depths was done at different points along the plume-which were selected following the direction of the freshwater mass in the sea domain -in order to analyse several water constituents. The samples were acquired using a vacuum pump that collected water directly to shipboard glass bottles, by means of a device similar to the SWASS described in Durand et al. (2002). It consists in a floating plate connected to the vessel by Teflon tubes, allowing the sampling at different depths (in this case, at $0.0,0.05,0.1,0.2,0.3,0.5$, 0.75 and $1.0 \mathrm{~m}$ ). The collected samples were refrigerated and taken to the laboratory, where they were divided into several proportional parts due to the different conservation procedures employed depending on the parameter to be determined. The samples were conserved following the APHA (1995) recommendations. The accuracy of the laboratory estimations of salinity is \pm 0.005 ppt.

During both field experiments, meteorological data measured every 10 minutes at L'Ampolla and hourly-mean river flow rates at Tortosa (see Fig. 1) were supplied by external institutions. The data acquisition campaign was completed with a thorough bathymetric scan of the river's last $42 \mathrm{~km}$.

Salinity measurements during both campaigns revealed the main physical characteristics of the river plume, particularly the thickness of the freshwater layer (less than $0.5 \mathrm{~m}$ ), and the high sensitivity of the plumes' shape and extension to the river discharge rate, the wave/current conditions and, especially, the local wind. As observed during the field campaigns, the overall spreading of the plume follows the direction of the wind even for relatively low wind velocities (less than $4 \mathrm{~m} / \mathrm{s}$ ). Therefore, the persistence of the river plume in a given direction depends on the wind variability, which is of the order of hours (Sierra et al., 2002).

\section{River plume modelling}

The hydrodynamic and transport models described above have been used to simulate the evolution of the river plume originated from the freshwater discharge of the Ebro River into the Mediterranean Sea. This study focuses on the vicinity of the river mouth and considers only the forcing due to the wind and the freshwater flow. Due to the small river discharge rates and the direction of the prevailing winds, the river plume will extend over the continental shelf and will not interact with the shelf edge flow. Consequently, mesoscale circulation effects considered in previous works (Espino et al., 1998; Maidana et al., 2002) are not taken into account. At 
open sea boundaries, therefore, a zero normal gradient condition is imposed on the flow, and the discharge velocity is specified at the rivermouth as a function of the assumed discharge rate. At solid boundaries, impermeability and no-slip conditions are imposed, whereas at the seabed a slip condition is considered, and the bottom shear stress is estimated using a quadratic formulation.

In all the cases presented, a constant $v_{\mathrm{H}}\left(=80 \mathrm{~m}^{2} / \mathrm{s}\right)$ was employed, and a mixing length model was used to estimate the vertical eddy viscosity. Although a better description of physical mixing is accomplished using one- and two-equation turbulence models (Xing and Davies, 1999, 2002), it was assumed here that the topographic effects on the spread of the plume would be more important than the differences introduced by the turbulence closure (Davies and Xing, 1999), so a simpler turbulence scheme was adopted. The configuration used here was adopted for the final model runs after yielding the best model response for a number of preliminary runs.

In order to calibrate the model suite, three climatologically different cases were considered, associated to the three main directions of the driving wind field.

Case 1). In the first case, coastal hydrodynamics are controlled by a homogeneous wind field from the ESE ( $97^{\circ}$ clockwise from the north), with a mean wind speed $W_{10}=3.8 \mathrm{~m} / \mathrm{s}$ and a river discharge of $113 \mathrm{~m}^{3} / \mathrm{s}$. Modelled results are compared to salinity measurements taken on July 111999 at different stations at and near the Ebro River mouth.

Case 2). In the second case, a homogeneous mean wind stress field associated with typical $\mathrm{S}$ $\left(190^{\circ}\right)$ wind conditions is considered $\left(W_{10}=2.2\right.$ $\mathrm{m} / \mathrm{s}$ ), with a mean river discharge of $167 \mathrm{~m}^{3} / \mathrm{s}$. A comparison is performed between salinity measurements taken on February 42000 at different locations in front of the river mouth, and the results given by the transport model.

Case 3). In the third case, the effects of a wind from the NNW $\left(335^{\circ}\right)$ are considered. The mean wind velocity is $W_{10}=4.6 \mathrm{~m} / \mathrm{s}$ and the mean river discharge flow is taken as $149 \mathrm{~m}^{3} / \mathrm{s}$. A qualitative comparison is presented between modelled plume contours and a satellite plume image obtained on July 61997.

\section{Hydrodynamics}

The circulation obtained with the hydrodynamic model for the three defined cases is shown in Fig-
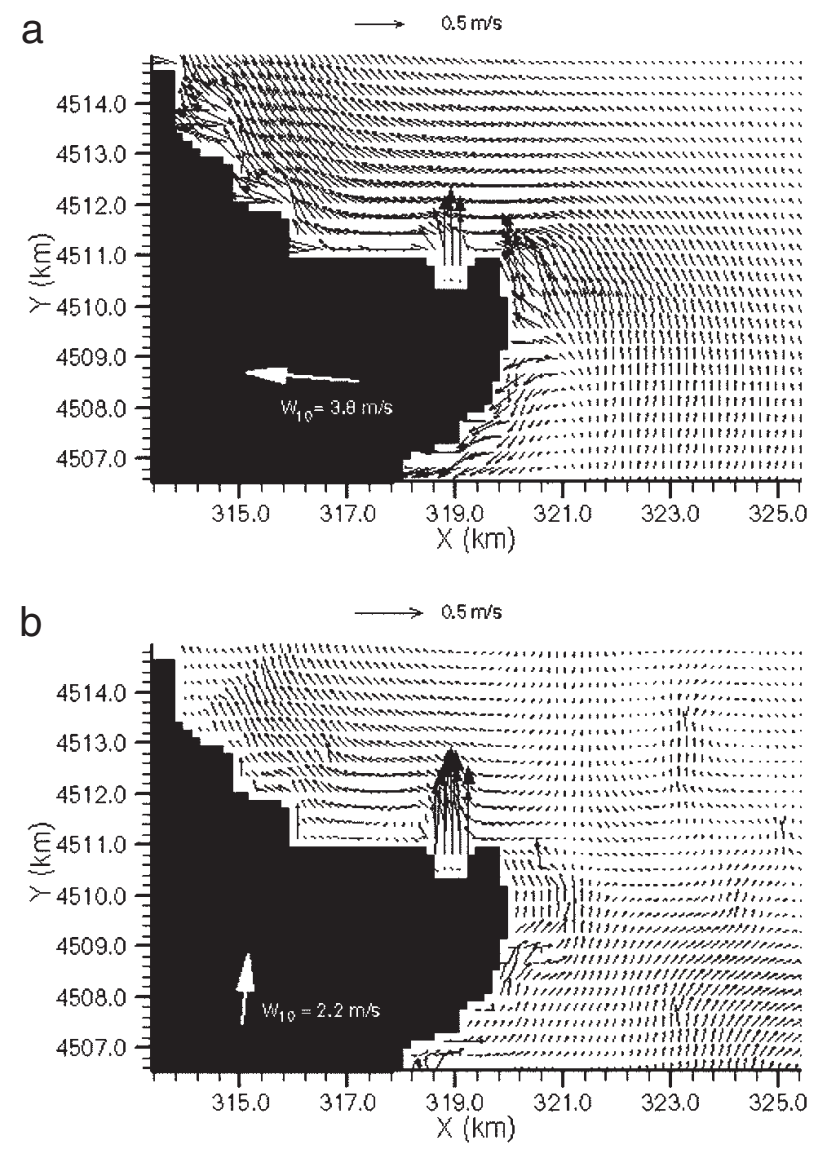

FIG. 2. - Close-up of the current field (surface layer) near the river mouth induced by a wind blowing from a ) the ESE (Case 1); and b) the $\mathrm{S}$ (Case 2).

ures 2 and 3. In all cases, the mean flow is strongly controlled by the prevailing wind, except in the neighbourhood of the river mouth, where the momentum of the freshwater discharge dominates. In Case 1 (Fig. 2a) the circulation pattern splits at the easternmost tip of the Ebro Delta, following a general southward direction along the southern hemidelta coast, and an overall northward direction on the northern half, following the coast. The river outflow affects the region nearest the river mouth, but its effects are rapidly overcome by coastal currents. Although the river discharge velocity is quite large (of the order of $1 \mathrm{~m} / \mathrm{s}$ ), the momentum of the freshwater jet is rapidly lost, and its trajectory becomes deflected due to the ambient current. Case 2 (Fig. 2b) shows a similar pattern near the river mouth, though in this case the river discharge velocity is somewhat larger and deflection occurs further offshore; the interaction between the wind-induced circulation and the riverine discharge generates a small cyclonic gyre immediately to the west of the river mouth. Other gyres, both cyclonic and anticyclonic, can be observed at the northern part of the 


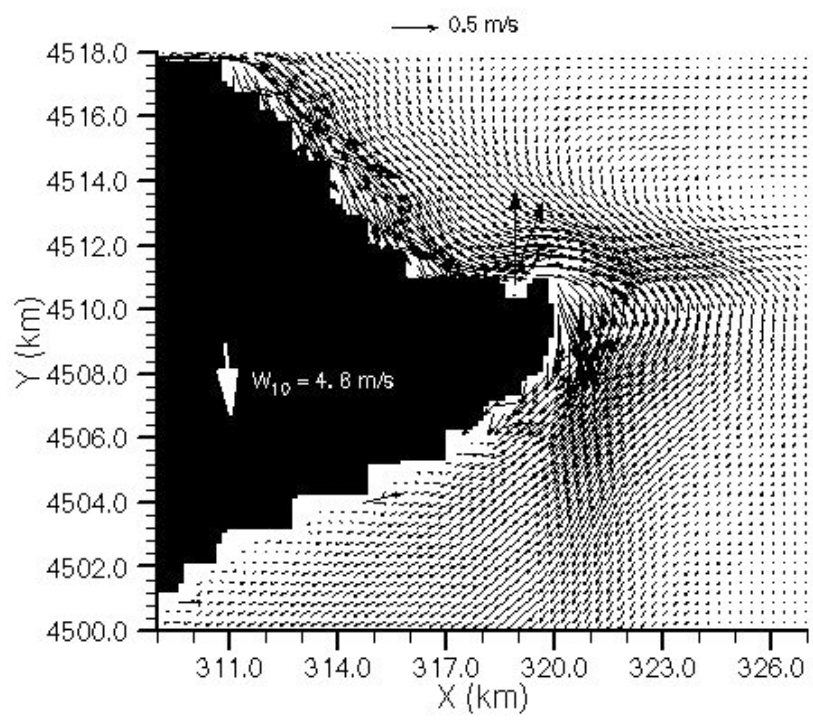

FIG. 3. - Close-up of the current field (surface layer) near the river mouth induced by a wind blowing from the NNW (Case 3).

domain. Away from the region of river influence, coastal currents follow a general northward direction, driven by the dominant wind and the effects of the bathymetry on the flow. Xing and Davies (2002) and Gjevik et al. (2002) also observed this topographic steering of the flow along the shelf.

The third case (Fig. 3) presents a different hydrodynamic pattern. Here, the general circulation is in a southward direction, along the coast and following the isobaths, with a cyclonic gyre to the northeast of the Delta. Again, the coastal circulation rapidly deflects the river discharge.

The differences observed in the circulation patterns obtained from the hydrodynamic model suggest that, for river discharges lower than $200 \mathrm{~m}^{3} / \mathrm{s}$, the spreading of the freshwater plume will be highly dependent on the prevailing wind field, as suggested by field observations (Sierra et al., 2002). In particular, for Cases 1 and 2 the plume extent is expected to be limited to the northern part of the delta, whereas for Case 3 the plume is going to "spill" over the easternmost tip of the Delta, following the coast to the south.

\section{Transport}

The simulation of the freshwater river discharge was performed in all three cases for intervals of between 10 and 24 hours (depending on the current velocity at the river mouth), using the hydrodynamic fields presented in the previous section. Turbulent dispersion was simulated with equations (11) using different values for the fit coefficients. These values were $750-950$ for $c_{L}$ and 750 for $c_{T}$. The total number of Lagrangian elements in each simulation ranged from 34,000 to 53,000 , depending on the simulation length. The plume shapes obtained from the transport model for Cases 1 and 2 are depicted in Figure 4, in the form of salinity contours.

As we expected after seeing the corresponding wind-induced hydrodynamic field, the plumes spread out across the northern hemidelta waters, following the coast. The plume spread appears to be larger in Case 2 and, since the diffusion coefficients have not varied much from one case to another, this extra-spreading must be due to the current field characteristics. In both cases the modelled freshwater plume encompasses the region in which measurements were made, and the comparison between modelled and measured water salinity at the stations shown in Figure 4 is presented in Figures 5 and 6. Due to the large number of sampling stations in each case (approximately 150 for Case 1 , and about 60 for Case 2), only those for which vertical profiles were obtained are used to compare the surface salinity with the values given by the transport model.
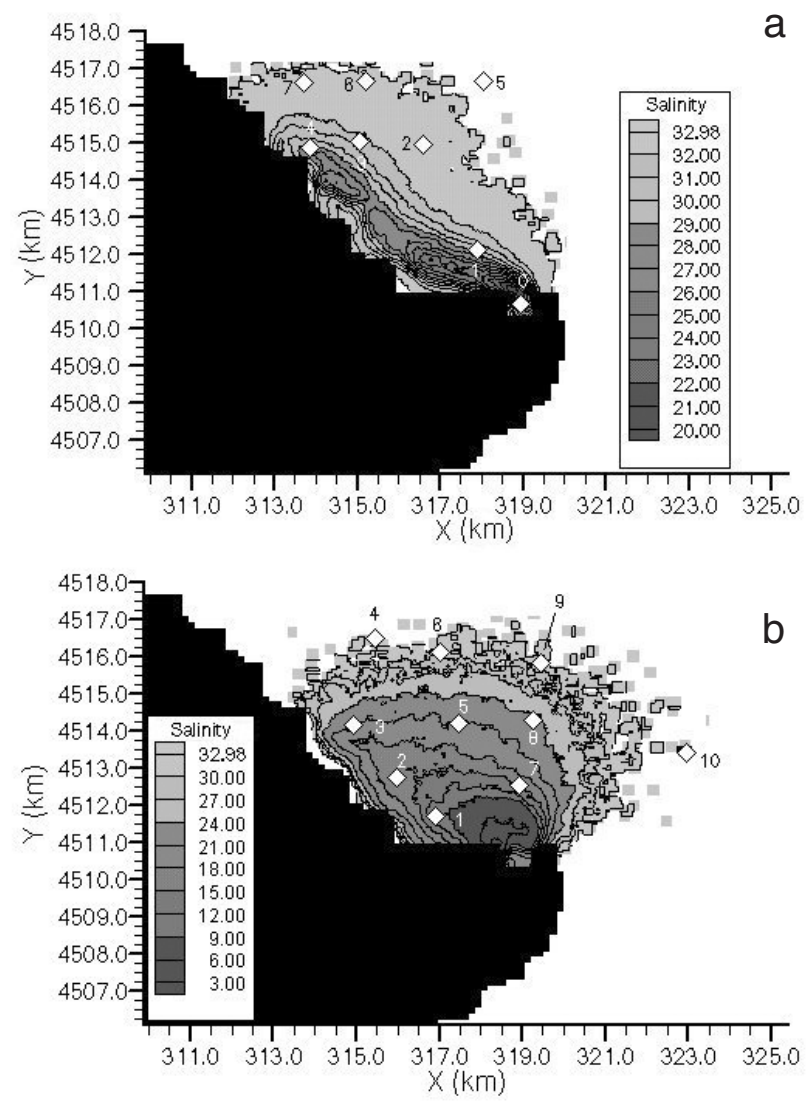

FIG. 4. - Plume resulting from the simulation of the Ebro River discharge for a) Case 1, and b) Case 2. Measuring stations used for lcomparison with modelled data are numbered in the figure. 

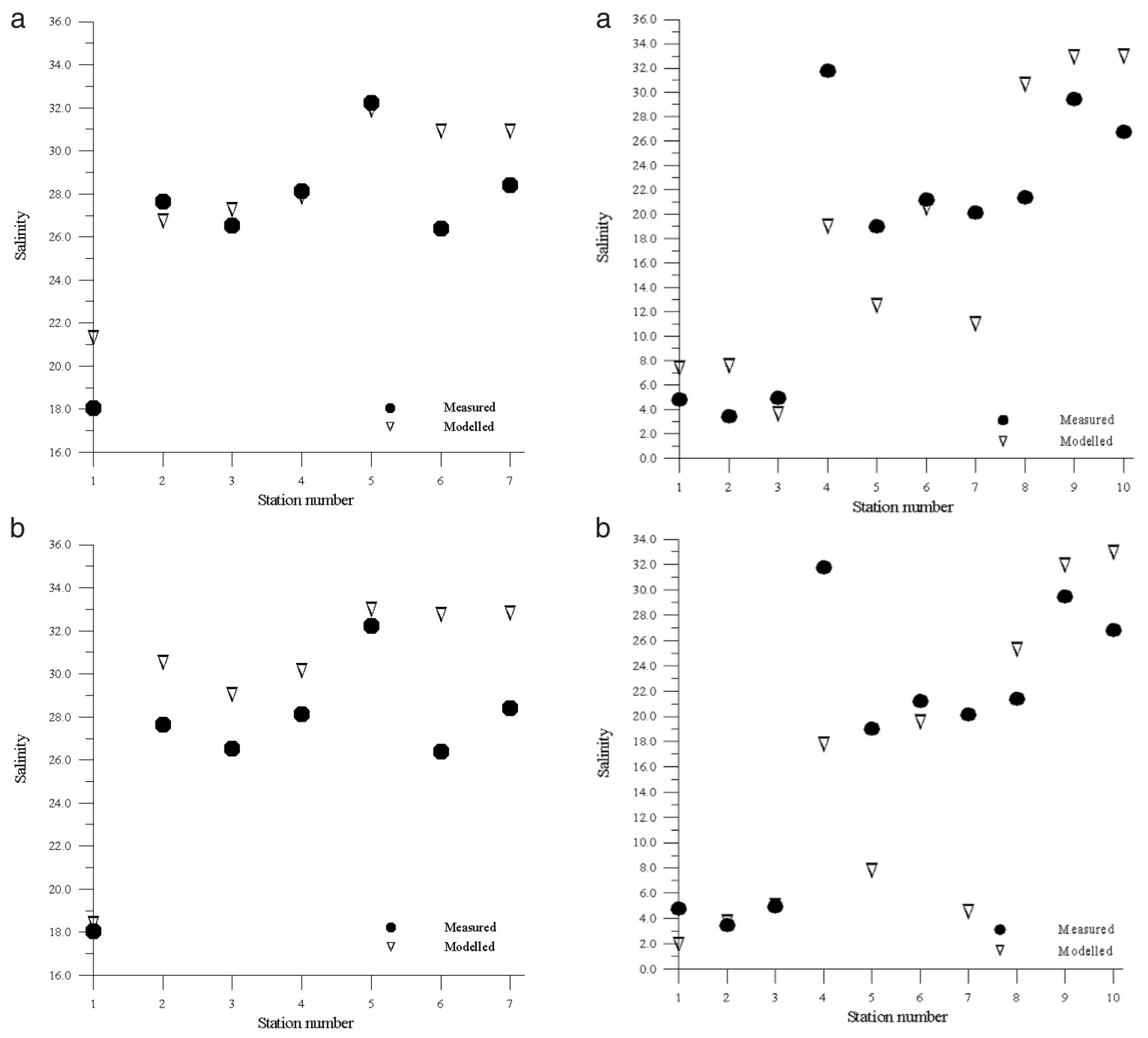

FIG. 5. - Measured and modelled salinity values (for Case 1) at the positions shown in Figure 4a (stations 1 to 7 ). The modelled values were computed using the $\mathrm{BC}$ method with $6,000 \times 6,000 \times 10 \mathrm{~m}$ (a) and $3,000 \times 3,000 \times 10 \mathrm{~m}(\mathbf{b})$ integration volumes.

The agreement between modelled and measured values appears to be satisfactory for Case 1 at most of the measuring stations (Fig. 5a), although the adjustment quality tends to decrease at the plume edge and close to the river mouth. In both regions, the "effective" volume occupied by Lagrangian particles is smaller than the integration volume defined in the mapping algorithm, and salinity values are therefore miscalculated. This argument is reinforced by the fact that smaller integration volumes lead to a better agreement at station 1, but increase the error obtained at the remaining locations (Fig. 5b). Another explanation for the worse performance of the

FIG. 6. - Measured and modelled salinity values (for Case 2) at the positions marked in Figure $4 \mathrm{~b}$ (stations 1 to 10). The modelled values were computed using the $\mathrm{BC}$ method with a 3,500 × 3,500 x 10 $\mathrm{m}$ integration volume (a), and the SPH method, with a $2,500 \mathrm{~m}$ integration length (b).

model near to the plume edge might be the difficulty of describing both the turbulence and the baroclinic driven exchange processes near the plume's edge in an appropriate manner.

On the other hand, the comparison between modelled and measured salinity, using two different mapping algorithms, shows that the agreement in Case 2 is not as satisfactory as in the previous case (Fig. 6). Although the SPH method seems to be somewhat more accurate than the $\mathrm{BC}$ method (Mestres, 2002), both show very large errors in relation to the measured salinity, especially at locations 


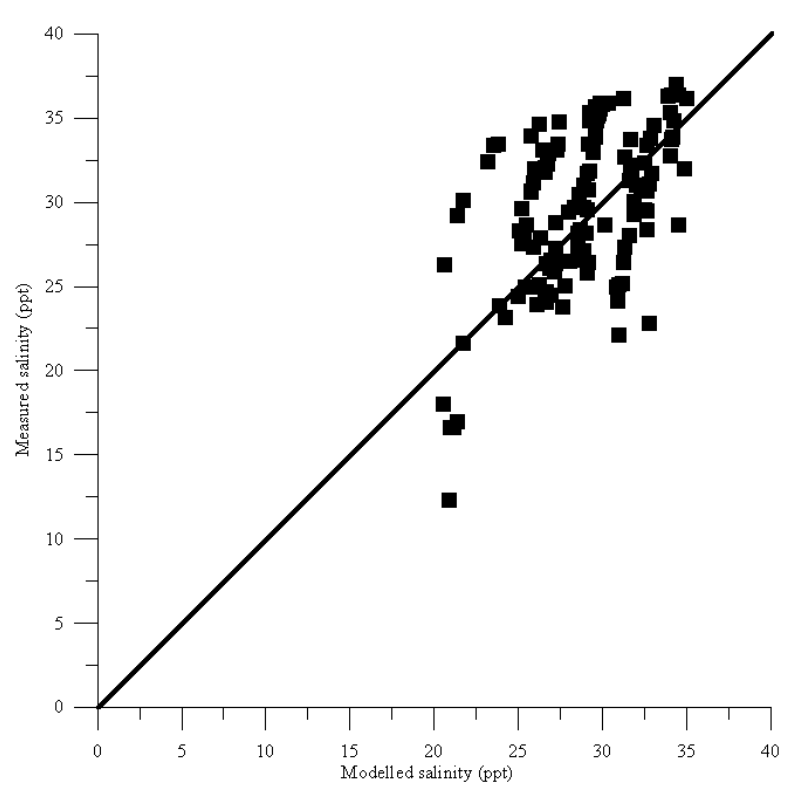

FIG. 7. - Measured vs modelled salinity at all field stations, for Case 1. The modelled salinities were found using the SPH mapping method, with a $5,000 \mathrm{~m}$ integration length.

situated further offshore. The data discrepancy may be due to the fact that salinity measurements at different stations were not simultaneous, therefore not corresponding to an instantaneous representation of the river plume at a given time $\mathrm{t}_{0}$. The time period existing between salinity measurements at different stations and the observed wind variability - not considered in the numerical modelling - might explain the differences between the observed salinity distribution and the modelled 'snapshot' of the plume.
Furthermore, the salinity obtained from the transport model in Case 1 was plotted against the surface salinity measured at all field stations (about 150), to evaluate the overall accuracy of the numerical output. The model results do not show a significant over- or underestimation of the salinity compared to the measured values, although there is some scatter in the numerical data, with a mean relative error referred to the field data of about 0.12 (Fig. 7).

The river plume in both cases extends towards the northern half of the delta, due to the coastal currents controlled predominantly by southern and eastern winds. For winds blowing from the opposite direction, the hydrodynamic pattern tends to "drag" the freshwater plume along the coast of the delta in a general southern direction, sometimes detaching it from the shallower waters and taking it into the open sea. The lack of measured salinity data under these wind conditions does not allow a quantitative comparison between model results and field data. To circumvent this limitation a qualitative comparison has been attempted using a satellite image of the plume (Fig. 8).

This comparison is depicted in Figures 8 and 9. The first figure shows a satellite image of the Ebro River's plume, taken on July 6 1997, whereas the modelled plume (using the hydrodynamic field of Case 3, depicted in Fig. 3) appears in Figure 9. These satellite data are extra-atmospheric radiances in red SPOT XS2 band centred at $650 \mathrm{~nm}$. In that channel, radiances are strongly dependent on the

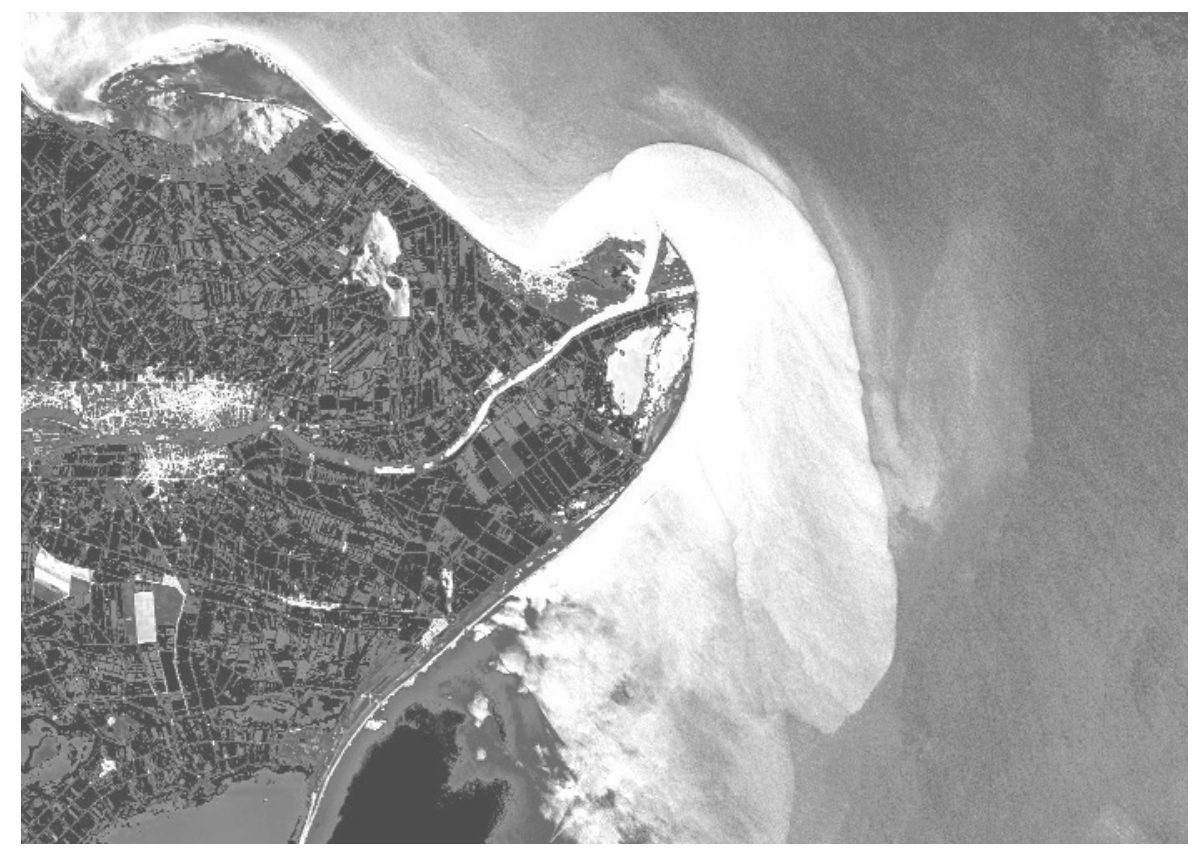

FIG. 8. - Satellite image of the freshwater plume from the Ebro River on July 6 1997. The grey scale refers to extra-atmospheric radiances measured by SPOT, HRV sensor, XS2 channel, @ C CNES. 


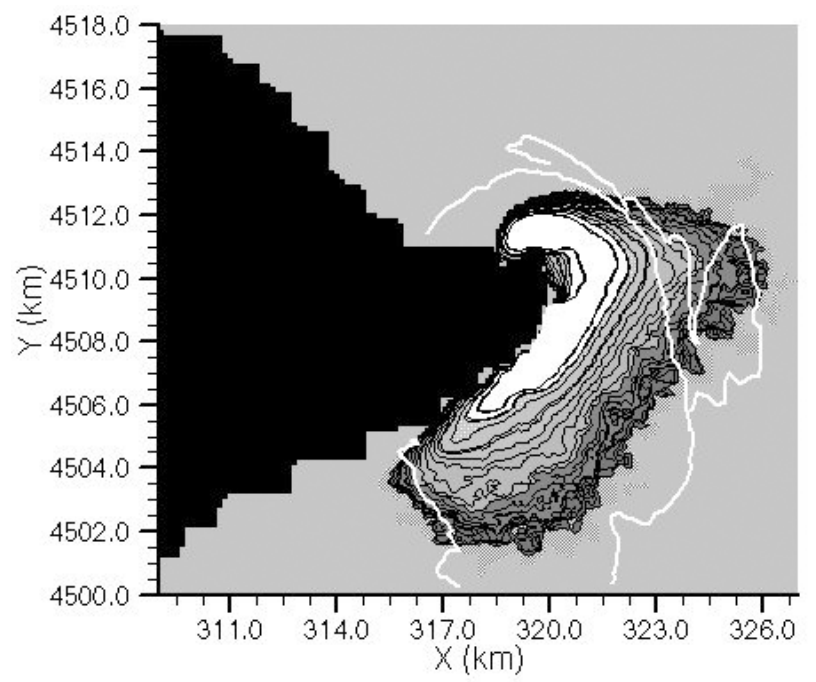

FIG. 9. - Plume resulting from the simulation of the Ebro River freshwater discharge, corresponding to Case 3 (hydrodynamics are depicted in Figure 3). The white lines correspond to the plume boundaries, digitised from the satellite image, while the black lines correspond to isohaline contours.

concentration of fine suspended particulate matter in the Ebro River plume (Ouillon, 2003). The patterns of concentration are similar to those of salinity when the plume is stratified, as was the case in July 1997. It can be seen in Figure 8 that the freshwater plume extends along the southern coast of the Delta (keeping off the northern waters) and that the modelled plume (Fig. 9) reproduces the observed one to an acceptable degree.

\section{Analysis of river discharge influence}

Additional runs of the hydrodynamic and transport models were performed for Case 1 in order to estimate the effect of the river's freshwater discharge on the coastal current field, and therefore on the trajectory followed by the river plume. Different values for the river flow $\left(\mathrm{Q}=1,400 \mathrm{~m}^{3} / \mathrm{s}, 750 \mathrm{~m}^{3} / \mathrm{s}\right.$, $500 \mathrm{~m}^{3} / \mathrm{s}$ and $400 \mathrm{~m}^{3} / \mathrm{s}$ ) were considered, keeping the remaining parameters (wind speed and direction, simulation time, diffusivities) constant. The hydrodynamic fields obtained from the simulation for the largest and smallest of the specified river outflows are shown in Figure 10, whereas Figure 11 shows the resulting freshwater plume.

The currents away from the river mouth are dominated by the effects of the wind and the bathymetry, so the circulation pattern is very similar for all values of Q. However, closer to the mouth of the Ebro, the hydrodynamics appear to depend very much on the river discharge. It is clear from Figure 10a that for the largest discharge value $\left(\mathrm{Q}=1,400 \mathrm{~m}^{3} / \mathrm{s}\right)$ the hydrody-
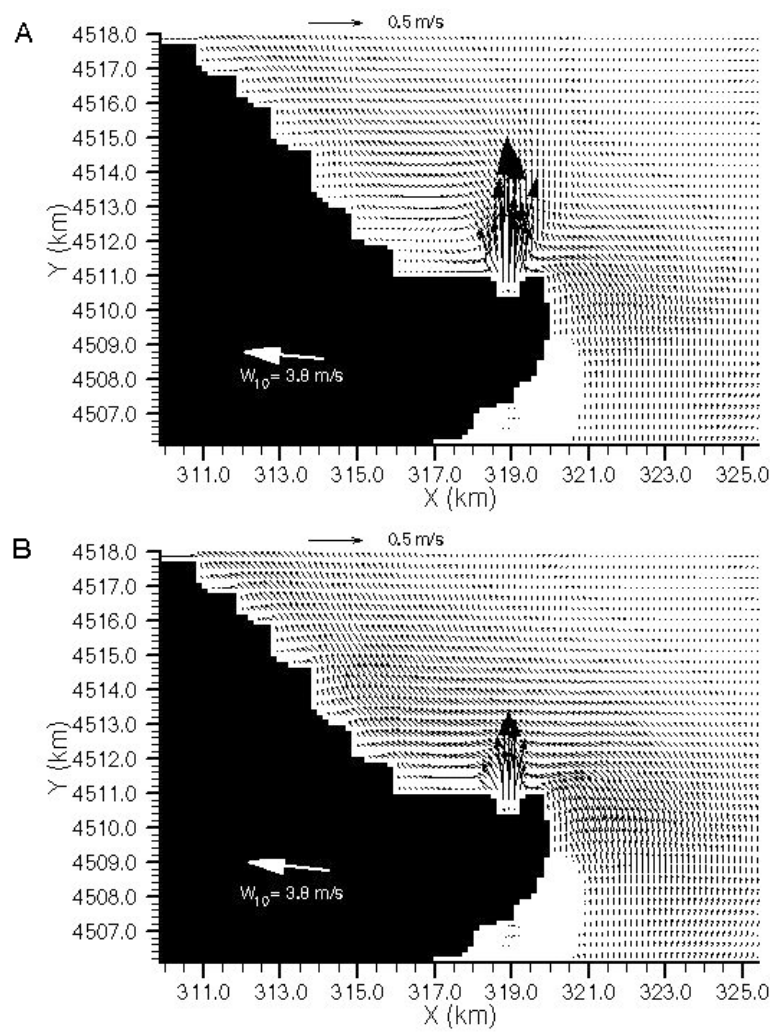

FIG. 10. - Circulation pattern (surface layer) induced by a ESE wind near the Ebro River mouth (Case 1) but with a) $Q=1,400 \mathrm{~m}^{3} / \mathrm{s}$, and b) $\mathrm{Q}=400 \mathrm{~m}^{3} / \mathrm{s}$.
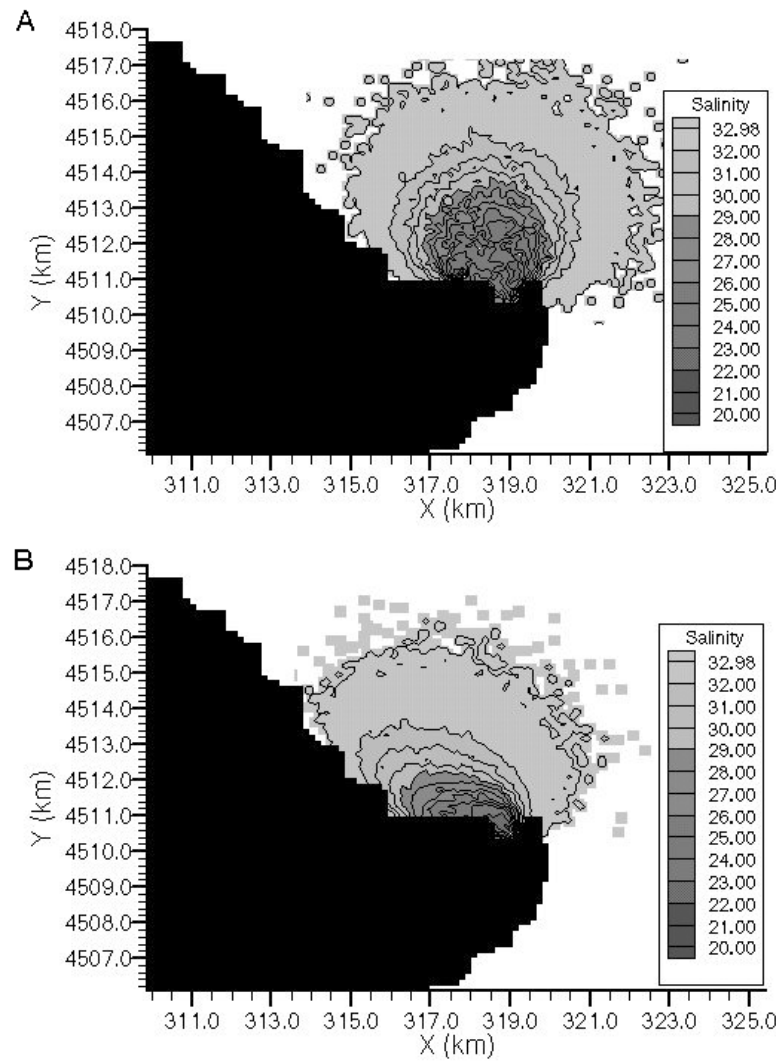

FIG. 11. - Plume resulting from the simulation of the Ebro River discharge with a) $\mathrm{Q}=1,400 \mathrm{~m}^{3} / \mathrm{s}$, and b) $\mathrm{Q}=400 \mathrm{~m}^{3} / \mathrm{s}$. The wind field is that defined for Case 1 . 
namics near the river mouth are largely controlled by the freshwater outflow, while the effects of the wind on the currents are only evident away from the discharge area. A similar circulation pattern results when the river discharge is halved $\left(\mathrm{Q}=750 \mathrm{~m}^{3} / \mathrm{s}\right)$, although in this case the influence of the river is not as dominant as in the previous one. A characteristic feature of both cases is the development of a cyclonic gyre on the western side of the freshwater flow, due to the interaction between the river discharge and the coastal currents. For the smaller river outflows, $\mathrm{Q}=$ $500 \mathrm{~m}^{3} / \mathrm{s}$ and $\mathrm{Q}=400 \mathrm{~m}^{3} / \mathrm{s}$ (Fig. 10b), the effects of the freshwater momentum are restricted to the region closest to the river mouth, and the currents become mainly wind-driven fairly quickly.

The spreading of the freshwater plume somehow reflects the behaviour of the current field. For large values of $\mathrm{Q}$, the plume is clearly governed by the river momentum, extending northwards from the river mouth; however, part of the freshwater is dragged to the west due to the small scale eddy mentioned above. For smaller river flows, the spreading of the plume is predominantly wind-driven, and it extends westward along the northern coast of the Delta. The results also agree with those reported by Durand et al. (2002), who found that the extension of the river plume was limited for regular river discharge rates.

From the modelled cases it appears that, under the assumed modelling conditions, a freshwater outflow of about $400 \mathrm{~m}^{3} / \mathrm{s}$ defines the limit above which the effects of the river's momentum overpowers the influence of the wind on the hydrodynamics near the river mouth and therefore determine the evolution of the freshwater plume. This threshold agrees with the values of freshwater flow which have been observed to wash away the salt wedge in the River Ebro (Ibáñez et al., 1997; Sierra et al., 2003).

\section{CONCLUSIONS}

Two numerical models have been used to simulate the hydrodynamics and freshwater dispersion from the mouth of the Ebro River, on the northeastern Spanish Mediterranean coast. Three climatologically different cases characterised by different wind fields and river discharge rates were modelled. The resulting salinity values were compared with experimental data measured at a number of locations for the first two cases, whereas a qualitative comparison was performed for the third case using a satellite image of the river plume.
In all cases (characterised by low-velocity winds and moderate river discharges), the modelled hydrodynamic field shows that, for regular river outflows, in spite of the weakness of the wind, meteorological forcing is the main driving agent for the currents over the whole domain. Over the shelf, topographic steering has been observed, in agreement with previous studies by other authors, whereas it appears that the effects of the river's discharge are significant only near the river mouth.

For regular freshwater discharge rates, the spatial extension of the plume is limited. When the dominant wind is from the east or south, the freshwater extends to the north and west of the mouth, owing to the combined effects of coastal current and river momentum. For northern winds, the freshwater plume is "dragged" to the east of the mouth, and then to the south along the coast of the delta.

Nevertheless, for higher river discharge rates (up to $400 \mathrm{~m}^{3} / \mathrm{s}$ ), the spreading of the river plume under similar wind conditions becomes controlled mainly by the freshwater momentum, extending northwards. This value and that proposed in the literature to wash away the salt wedge in the Ebro River appear to be very similar.

The quantitative analysis of the simulated results reveals that the modelled salinity agrees reasonably well with measured data for Case 1 (east wind), with a mean relative error of about $8 \%$ and a maximum relative error of $19 \%$ at the considered stations. The errors for Case 2 (south wind) are larger, with a mean and maximum relative error of 29 and $80 \%$ respectively. These larger errors are due to the fluctuating wind direction, which does not allow stationary conditions to be reached. In both cases, the accuracy of the simulation depends on the integration value adopted within the concentration mapping module; for a given integration value, the accuracy at different locations differs owing to the presence of solid boundaries and the plume front.

For Case 3 (NNW wind), the general shape of the modelled plume appears to match the satellite image to an acceptable degree, although the internal structure of the real plume has not been resolved.

The methodology proposed in this paper appears to be useful and accurate enough to simulate the dynamics of the Ebro River freshwater plume in a relatively fast and simple way, although the numerical results could not be validated under high river discharge conditions due to the lack of corresponding field data. 


\section{ACKNOWLEDGEMENTS}

The authors wish to acknowledge the support given to this work by the EU projects FANS and PIONEER (EC MAST Research Programme, contracts No. MAS3-CT95-0037 and MAS3-CT980170 respectively), the CYTMAR Programme from the Spanish Comisión Interministerial de Ciencia y Tecnología (project MAR96-1856), and the CNES for the SPOT satellite image.

\section{REFERENCES}

APHA - 1995. Standard methods for the examination of water, wastewater and sediments. 19 $9^{\text {th }}$ Edition. American Public Health Association Inc., Washington, DC, USA.

Baumert H., H. Burchard and E. Kleine. - 1997. On secondmoment closures for marine turbulence. A review. $29^{\text {th }}$ Liège Colloquium on Marine Hydrodynamics. Turbulence revisited. Liège, May 5-9.

Broche P., J-L. Devenon, P. Forget, J-C. Maistre, J-J. Naudin and G. Cauwet. - 1998. Experimental study of the Rhone plume. Part I: physics and dynamics. Oceanol. Acta, 21: 725-738.

Burchard, H. and K. Bolding. - 2001. Comparative analysis of four second-moment turbulence closure models for the oceanic mixed layer. J. Phys. Oceanogr., 31: 1943-1968.

Casulli, V. and C. Stelling. - 1996. Simulation of three dimensional, non-hydrostatic free-surface flows for estuaries and coastal seas. In: M. Spaulding and R. Cheng (eds.), Proc. $4^{\text {th }}$ Int. Conf. on Estuarine and Coastal Modelling, pp. 1-12, San Diego, CA, USA.

Chao, S.-Y. - 1987. Wind-driven motion near inner shelf fronts. $J$. Geophy. Res., 92: 3849-3860.

Chao, S.-Y. - 1988. River forced estuarine plumes. J. Phys. Oceanogr., 18: 2137-2149.

Chao, S.-Y. and W.C. Boicourt. - 1986. Onset of estuarine plumes. J. Phys. Oceanogr., 16: 2137-2149.

Davies A. and J. Xing- 1999. Sensitivity of plume dynamics to the parameterization of vertical mixing. Int. J. Num. Meth. Fluids, 30: 357-405.

Durand N., A. Fiandrino, P. Fraunié, S. Ouillon, P. Forget and J.-J. Naudin. - 2002. Suspended matter dispersion in the Ebro ROFI: an integrated approach. Cont. Shelf Res., 22: 267-284.

Espino, M., A. Sánchez-Arcilla and M.A. García. - 1998. Windinduced mesoscale circulation off the Ebro delta, NW Mediterranean: a numerical study. J. Mar. Syst., 16: 235-251.

Estournel, C., V. Kondrachoff, P. Marsaleix and R.Véhil. - 1997. The plume of the Rhone. Numerical simulation and remote sensing. Cont. Shelf Res., 17: 899-917.

Fennel, W. and A. Mutzke. - 1997. The initial evolution of a buoyant plume. J. Mar. Syst., 12: 53-68.

Fichez, R., T.D. Jickells and H.M. Edmunds. - 1992. Algal blooms in high turbidity, a result of the conflicting consequences of turbulence on nutrient cycling in a shallow water estuary. Estuar. Coast. Shelf Sci., 35: 577-593.

Font J. - 1990. A comparison of seasonal winds with current on the continental slope of the Catalan Sea. J. Geophy. Res., 95: $1537-1545$.

Font J., J. Salat and A. Julià. - 1990. Marine circulation along the Ebro continental margin, Mar. Geol., 95: 165-177.

Font J., E. García-Ladona and E. Gorriz. - 1995. The seasonality of mesoscale motion in the Northern Current of the Western Mediterranean: several years of evidence. Oceanol. Acta, 18(2): 207-219

Froidefond, J.M., A.M. Jegou, J. Hermida, P. Lazure and P. Castaing. - 1998. Variability of the Gironde turbid plume by remote sensing. Effects of climatic factors. Oceanol. Acta, 21: 191-207.

Garcia, M.A. and A. Ballester. - 1984. Notas acerca de la meteorología y la circulación local en la región del delta del Ebro (1980-1981). Invest. Pesq., 48(3): 469-493.
García, M.A., A. Sánchez-Arcilla, J. P. Sierra, J. Sospedra and J. Gómez. - 1993. Wind waves off the Ebro Delta, NW Mediterranean. J. Mar. Syst., 4: 235-262.

García Berdeal I., B.M. Hickey and M. Kawase. - 2002. Influence of wind stress and ambient flow on a high discharge river plume. J. Geophys. Res., 107(C9), 3130, doi: 10.1029/ 2001JC000932.

Garvine, R.W. - 1987. Estuarine plumes and fronts in shelf waters: a layer model. J. Phys. Oceanogr., 17: 1877-1896.

Garvine, R.W. - 1995. A dynamical system for classifying buoyant coastal discharges. Cont. Shelf Res., 15(13): 1585-1596.

Gingold, R. and J. Monaghan. - 1982. Kernel estimates as a basis for general particle methods in hydrodynamics. J. Comput. Phys., 46: 429-453.

Gjevik B., H. Moe and A. Ommundsen. - 2002. Idealized model simulations of barotropic flow on the Catalan shelf. Cont. Shelf Res., 22: 173-198.

Grimes C. and M. Kingsford. - 1996. How do riverine plumes of different sizes influence fish larvae: do they enhance recruitment? Mar. Freshwater Res., 47: 191-208.

Holly, F. - 1985. Dispersion in rivers and coastal waters. In: P. Novak (ed.), Developments in Hydraulic Engineering-3, Chapter 1, Elsevier, London.

Ibáñez, C., N. Prat and A. Canicio. - 1996. Changes in the hydrology and sediment transport produced by large dams on the lower Ebro River and its estuary. Regul. River., 12: 51-62.

Ibáñez, C., D. Pont and N. Prat. - 1997. Characterization of the Ebre and Rhone estuaries: A basis for defining and classifying saltwedge estuaries. Limnol. Oceanogr., 42: 89-101.

Jiménez, J. - 1996. Evolución costera en el Delta del Ebro. Un proceso a diferentes escalas de tiempo y espacio. $\mathrm{PhD}$ thesis, Universitat Politècnica de Catalunya, Spain.

Johns, B., P. Marsaleix, C. Estournel and R. Véhil. - 1992. On the wind-driven coastal upwelling in the Gulf of Lions. J. Mar. Syst., 3: 309-320.

Jouanneau, J.M. and C. Latouche. - 1982. Estimation of fluxes to the ocean from mega-tidal estuaries under moderate climates and the problems they present. Hydrobiologia, 91: 23-29.

Kourafalou, V.H., L.-Y. Oey, J.D. Wang and T.N. Lee. - 1996a The fate of river discharge on the continental shelf, 1. Modelling the river plume and the inner shelf coastal current. J. Geophys. Res., 101: 3415-3434.

Kourafalou, V.H., T. N. Lee, L.-Y. Oey and J. D. Wang. - 1996b. The fate of river discharge on the continental shelf, 2. Transport of coastal low-salinity waters under realistic wind and tidal forcing. J. Geophys. Res., 101: 3435-3455.

Lazure, P. and A.M. Jegou. - 1998. 3D modelling of seasonal evolution of Loire and Gironde plumes on Biscay Bay continental shelf. Oceanol. Acta, 21: 165-177.

Lentz, S.J. and R. Limeburner. - 1995. The Amazon river plume during AMASSEDS: Spatial characteristics and salinity variability. J. Geophy. Res., 100: 2355-2375.

Luyten, P.J., E. Deleersnijder, J. Ozer, and K.G. Ruddik. - 1996. Presentation of a family of turbulence closure models for stratified shallow water flows and preliminary application to the Rhine outflow region, Cont. Shelf Res., 16: 101-130.

Maidana, M.A., J.-J. Naudin, M. Espino, M.A. García. and A. Sánchez-Arcilla. - 2002. Feasibility and usefulness of steadystate calculations of the mean circulation in the vicinity of the Ebro mouth. Model tests against field data. Cont. Shelf Res., 22: 229-245.

Marsaleix, P., C. Estournel, V. Kondrachoff, and R. Vehil. - 1998 A numerical study of the formation of the Rhone River plume. J. Mar. Syst., 14: 99-115.

Martínez, R., E. Movellán, C. Mösso, J. P. Sierra. and A. Olivos. 1999. Pioneer II Field Campaign. Preliminary report, Research Report RR-LIM/AHC-99-4, Barcelona, Spain.

Martínez, R., E. Movellán, C. Mösso, J.P. Sierra and L. Marotta. 2000. Pioneer IV Field Campaign. Preliminary report, Research Report RR-LIM/AHC-00-1, Barcelona, Spain.

Mestres, M. - 2002. Three-dimensional simulation of pollutant dispersion in coastal waters. PhD thesis, Universitat Politècnica de Catalunya, Barcelona, Spain.

Morris, A.W., J.I. Allen, R.J. Howland and R.G. Wood. - 1995. The estuary plume zone: source or sink of land-derived nutrient discharges?. Estuar. Coast. Shelf Sci., 40: 387-402.

O'Donnell, J. - 1990. The formation and fate of a river plume: a numerical model. J. Phys. Oceanogr., 20: 551-569. 
Oey, L.-Y. and G.L. Mellor. - 1993. Subtidal variability of estuarine outflow, plume and coastal current: a model study. J. Phys. Oceanogr., 23: 164-171.

Ouillon, S. - 2003. An inversion method for reflectance in stratified turbid waters. Int. J. Remote Sensing, 24: 535-558.

Pinazo, C., P. Marsaleix, B. Millet, C. Estournel and R. Véhil. 1996. Coupled modelling of physical and biological processes in the Gulf of Lions (northwestern Mediterranean): spatial and temporal variability. J. Mar. Syst., 7: 161-191.

Salat, J., M.A. García, A. Cruzado, A. Palanques, L. Arín, D. Gomis, J. Guillén, A. de León, J. Puigdefàbregas, J. Sospedra and Z. Velásquez. - 2002. Seasonal changes of water mass structure and shelf slope exchanges at the Ebro Shelf (NW Mediterranean). Cont. Shelf Res., 22: 327-348.

Siegel, H., M. Gerth and A. Mutzke. - 1999. Dynamics of the Oder river plume in the Southern Baltic Sea: satellite data and numerical modelling. Cont. Shelf Res., 19: 1143-1159.

Sierra, J.P., A. Sánchez-Arcilla, J. González del Río, J. Flos, E. Movellán, C. Mösso, R. Martínez, M. Rodilla, S. Falco and I. Romero. - 2002. Spatial distribution of nutrients in the Ebro estuary and plume. Cont. Shelf Res., 22: 361-378.

Sierra, J.P., A. Sánchez-Arcilla, P.A. Figueras, J. González del Río, E.K. Rassmussen and C. Mösso. - 2003. Effects of discharge reductions on salt wedge dynamics of the Ebro River. River
Research and Applications (in press).

Stumpf, R.P., G. Gelfenbaum and J.R. Pennock. - 1993. Wind and tidal forcing of a buoyant plume, Mobile-Bay, Alabama. Cont. Shelf Res., 13: 1281-1301.

Tompson, A. and L. Gelhar. - 1990. Numerical simulation of solute transport in three- dimensional randomly heterogeneous porous media. Water Resour. Res., 26(10): 2541-2562.

Umlauf L., H. Burchard and K. Hutter. - 2003. Extending the k-w turbulence model towards oceanic applications. Ocean Modelling, 5: 295-218.

Weaver, A.J. and W.W. Hsieh. - 1987. The influence of buoyancy flux from estuaries on continental shelf circulation. J. Phys. Oceanogr., 17: 2127-2140.

Xing, J. and A.M. Davies. - 1999. The effect of wind direction and mixing upon the spreading of a buoyant plume in a non-tidal regime. Cont. Shelf Res., 19: 1437-1483.

Xing, J. and A.M. Davies. - 2002. Influence of topographic features and along shelf flow upon the Ebro plume. Cont. Shelf Res., 22: 199-227.

Yankovsky, A.E. and D.C. Chapman. - 1997. A simple theory for the fate of buoyant coastal discharges. J. Mar. Res., 27: 13861401.

Scient. ed.: J. Font 
